\title{
Solubility of Carbon Dioxide in Strongly Basic Ionic Liquid
}

\author{
Jun Kyung Sung, Sung Hyun Kim, ${ }^{\dagger}$ Minserk Cheong, ${ }^{\ddagger * *}$ and Ilhyun Baek* \\ Climate Change Technology Research Division, Korea Institute of Energy Research, 102 Gajeong-ro, Yuseong-gu, \\ Daejeon 305-343, Korea. *E-mail: ihbaek@kier.re.kr \\ ${ }^{\dagger}$ Department of Chemical Engineering, Korea University, Seoul 136-701, Korea \\ ${ }^{\star}$ Department of Chemistry and Research Institute for Basic Sciences, Kyung Hee University, Seoul 130-701, Korea \\ *E-mail: mcheong@khu.ac.kr
}

Received June 15, 2010, Accepted August 11, 2010

\begin{abstract}
For the purpose of developing advanced new absorbents for carbon dioxide, ionic liquids (ILs) are considered as alternative materials due to their superior properties to conventional organic solvents. Since low $\mathrm{CO}_{2}$ solubility in ionic liquids is a major concern for their application as absorbents, it is essential to focus on improving $\mathrm{CO}_{2}$ absorbing capability of ILs. In this paper, strongly basic ionic liquids, namely $\left[\mathrm{C}_{n}-\operatorname{mim}\right] \mathrm{OPh}(\mathrm{n}=2,4,6)$, have been synthesized and studied over a wide range of temperature and pressure changes. $\left[\mathrm{C}_{\mathrm{n}}-\mathrm{mim}\right] \mathrm{OPh}$ can be easily synthesized from corresponding $\left[\mathrm{C}_{\mathrm{n}}-\mathrm{mim}\right] \mathrm{Cl}$ and sodium phenoxide and has been found to be good $\mathrm{CO}_{2}$ absorbents.
\end{abstract}

Key Words: Strongly basic ionic liquid, Carbon dioxide capture, Phenolate-based ionic liquid, $\mathrm{CO}_{2}$ solubility

\section{Introduction}

Lately, controlling carbon dioxide emission is regarded as one of the hot issues all around the world. Uncountable researches related with efficient capturing of carbon dioxide are performed by various research groups to replace conventional carbon dioxide absorption methods using amines, ammonia, dry solvents or membranes. To be an ideal $\mathrm{CO}_{2}$ absorbent, it has to satisfy some primary requirements. $\mathrm{ACO}_{2}$ absorbent needs to have high $\mathrm{CO}_{2}$ solubility, high absorption rate, high $\mathrm{CO}_{2}$ selectivity, mild regeneration condition, thermal/chemical stability, low viscosity, and low volatility. ${ }^{1}$ Non-toxicity and low cost are also essential options for a good $\mathrm{CO}_{2}$ absorbent. Conventional processes have several critical problems such as high energy consumption for regeneration, degradation of solvents, volatility issues, and environmental hazard. ${ }^{2 \mathrm{a}, 2 \mathrm{~b}}$ One of the materials considered for replacing conventional solvents is an ionic liquid. Ionic liquids (ILs) are generally defined as salts existing in the molten state at ambient conditions, and mainly consist of an asymmetric organic cation and either an organic or an inorganic anion. ${ }^{3}$ Due to their superior unique properties, they are used in a large variety of applications in current chemical industries, such as in preparation of catalysts, separation processes, synthesis of nanoparticles, or as electrolytes. ${ }^{4}$ ILs have some unique solvent properties, such as high potential to dissolve many kinds of organic, inorganic materials and gases, very low vapor pressures, thermal and chemical stability. ${ }^{5}$ ILs also can be tuned to uncountable numbers by just varying the combination of cations and anions, which means that they are very flexible in structure and associated properties. ${ }^{6}$

These properties of ILs can easily attract researchers who are seeking more advanced solvents for capturing $\mathrm{CO}_{2}$. Bates et al. studied amino-functional ILs, ${ }^{7}$ and Yu et al. ${ }^{8 \mathrm{a}}$ and Huang et al. $^{8 \mathrm{~b}}$ suggested guanidinium-based ILs for $\mathrm{CO}_{2}$ absorption. Palgunadi et al. have studied the amide-based Brønsted acidic ILs as an alternative solvent to $\mathrm{CO}_{2}$ absorption. ${ }^{9}$ There are however some problems in using ionic liquids as commercial $\mathrm{CO}_{2}$ absorbents. First of all, ionic liquids are very expensive compared to amines and ammonia. But the research field of ILs is still an unexplored area, and their use is limited only to some specific areas. ${ }^{10}$ It is expected that the cost of ILs will steadily decrease as demand for these liquids increases. Also if the ILs can be recycled without any loss during regeneration, they can be used despite the initial cost. Another problem is low $\mathrm{CO}_{2}$ solubility of ILs. The capacity of dissolving $\mathrm{CO}_{2}$ in ILs is significantly lower than those of amines, ammonia, or any other commercial absorbents. This can be a critical problem for using ILs as an absorbent for $\mathrm{CO}_{2}$. But, once again, ILs can be tuned to uncountable numbers by just altering combination of cations and anions. It is estimated that more than $10^{18}$ types of ILs can be newly designed, and this means ILs have amazing chances and possibilities for better $\mathrm{CO}_{2}$ solubility and lower cost without losing ILs' great characteristics. The main purpose of this research is to find an alternative IL suitable for $\mathrm{CO}_{2}$ sorption considering solubility, cost, sorption rate, and regeneration as much as possible.

The mechanism of absorbing $\mathrm{CO}_{2}$ in commercial ILs is known to be physical absorption in 'free volume' of ILs. When physisorbing ILs are used, the most serious problem is viscosity because increased viscosity works as a hindrance to dissolving $\mathrm{CO}_{2}$. To minimize this problem, fluorinated anions such as $\mathrm{BF}_{4}^{-}, \mathrm{PF}_{6}{ }^{-}$and $\mathrm{Tf}_{2} \mathrm{~N}^{-}$can be used. These fluorinated anions show relatively strong affinities for $\mathrm{CO}_{2}$ but they make ILs very costly. ${ }^{11}$ Davis et al. proposed that the $\mathrm{CO}_{2}$ solubility of ILs can be improved by attaching a functional group such as amines. ${ }^{12 a}$ Amine functional group forms carbamate anion by reacting with $\mathrm{CO}_{2}$. In this method, ILs function as solvents as well, so no energy is needed to heat up water when stripping the absorbed $\mathrm{CO}_{2}$ as in conventional MEA processes. ${ }^{12 \mathrm{~b}}$ This concept still has some limitations like the increase of the viscosity of ILs due to the formation of zwitterionic carbamates. Also $\mathrm{CO}_{2}$ solubility is still low because two moles of amines 
are needed for capturing one mole of $\mathrm{CO}_{2}$. So we focused on finding another suitable candidate which will interact with $\mathrm{CO}_{2}$ as strongly as amines without the formation of undesirable carbamates. By choosing phenolate as the anion of an IL, we hoped to avoid the formation of the carbamate anion and increase the solubility of $\mathrm{CO}_{2}$ in the IL by forming 1:1 complex instead of 2:1 complex.

\section{Experimental}

General considerations. All chemical reagents were purchased from Aldrich Chemicals Co. and used as received. $\mathrm{CO}_{2}$ was purchased from Sin Yang Gas, Korea. ${ }^{1} \mathrm{H}$ NMR spectra were recorded on a $500 \mathrm{MHz}$ Bruker NMR spectrometer.

Synthesis of ionic liquids. $\left[\mathrm{C}_{\mathrm{n}}-\mathrm{mim}\right] \mathrm{Cl}(>98 \mathrm{wt} \%$ purity, $\mathrm{n}=$ $2,4,6)$ and sodium phenolate $\left(\mathrm{PhONa} \cdot 3 \mathrm{H}_{2} \mathrm{O}\right)(99 \mathrm{w} \mathrm{t} \%$ purity $)$ were purchased from C-Tri Korea and Sigma-Aldrich, respectively. They were kept in vacuum at $343 \mathrm{~K}$ for more than 10 hrs before use. ${ }^{13}\left[\mathrm{C}_{\mathrm{n}}\right.$-mim $] \mathrm{OPh}$ was prepared from metathesis reaction of $\left[\mathrm{C}_{\mathrm{n}}-\mathrm{mim}\right] \mathrm{Cl}$ with sodium phenolate according to the typical literature procedure. ${ }^{14}$ All crude ILs were purified by multiple washing with methylene chloride, passing through a few $\mathrm{cm}$-thick layer of celite 545 on glass filter (pore size is about $11 \mu \mathrm{m})$, and drying under a reduced pressure $(<1 \mathrm{mbar})$ at $80{ }^{\circ} \mathrm{C}$ for minimun $12 \mathrm{~h}$ prior to use. Purities of RTILs (room temperature ionic liquids) were better than $99 \%$ as deduced from ${ }^{1} \mathrm{H}$ NMR spectroscopy analysis. Water contents were below 5 ppm as determined by Karl Fischer titration (HUCOM System's Coulometric Moisture Analyzer). No residual chloride was detected by $\mathrm{AgNO}_{3}$ test. $^{15}$

[C 2 -mim] OPh: ${ }^{1} \mathrm{H}$ NMR (500 MHz, $\left.\mathrm{CDCl}_{3}, 298 \mathrm{~K}, \mathrm{TMS}\right) \delta$ 1.48 (t, 3H), 3.99 (s, 3H), 4.29 (q, 2H), 6.68-7.22 (m, 5H), 7.60 (s, 2H), $10.25(\mathrm{~s}, 1 \mathrm{H})$.

[C 4 -mim]OPh: ${ }^{1} \mathrm{H}$ NMR $\left(500 \mathrm{MHz}, \mathrm{CDCl}_{3}, 298 \mathrm{~K}, \mathrm{TMS}\right) \delta$ $0.86(\mathrm{t}, 3 \mathrm{H}), 1.24-1.28(\mathrm{~m}, 2 \mathrm{H}), 1.74-1.78(\mathrm{~m}, 2 \mathrm{H}), 3.96(\mathrm{~s}$, $3 \mathrm{H}), 4.17(\mathrm{t}, 2 \mathrm{H}), 6.65-7.27(\mathrm{~m}, 5 \mathrm{H}) 7.50(\mathrm{~s}, 1 \mathrm{H}), 7.51(\mathrm{~s}, 1 \mathrm{H})$, $10.29(\mathrm{~s}, 1 \mathrm{H})$.

[C $\mathbf{C}_{6}$-mim] OPh: ${ }^{1} \mathrm{H}$ NMR $\left(500 \mathrm{MHz}, \mathrm{CDCl}_{3}, 298 \mathrm{~K}, \mathrm{TMS}\right) \delta$ $0.77(\mathrm{t}, 3 \mathrm{H}), 1.16(\mathrm{~m}, 6 \mathrm{H}), 1.70(\mathrm{~m}, 2 \mathrm{H}), 3.85(\mathrm{~s}, 3 \mathrm{H}), 4.06(\mathrm{t}$, $2 \mathrm{H}), 6.54-7.19(\mathrm{~m}, 5 \mathrm{H}) 7.44(\mathrm{~s}, 1 \mathrm{H}), 7.45(\mathrm{~s}, 1 \mathrm{H}), 10.06(\mathrm{~s}, 1 \mathrm{H})$.

$\mathrm{CO}_{2}$ solubility measurement. In the present study, vapor liquid equilibrium (VLE) apparatus has been mainly used for

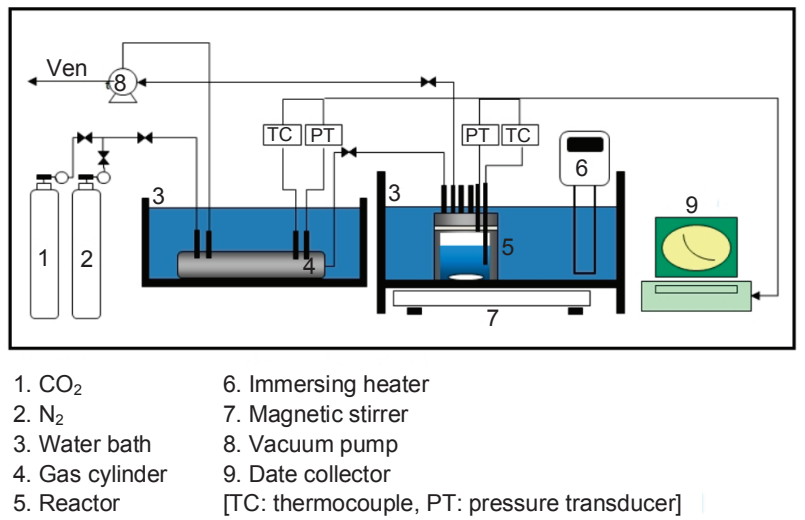

Figure 1. Schematic diagram of VLE apparatus. measuring solubility of $\mathrm{CO}_{2}$ in ILs and its schematic diagram has been shown in Figure 1. $\mathrm{CO}_{2}$ gas is stored into four reservoirs to a desired pressure up to 100 bar maximum. A known amount of $\mathrm{CO}_{2}$ gas is introduced into the reactor which is made of stainless steel and about $70 \mathrm{~cm}^{3}$ in size. Leak test was performed using $\mathrm{N}_{2}$ gas of $99.99 \%$ purity with similar pressure ranges before each measurement. A sample is weighed on a microbalance and put into the reactor before it is sealed tightly. Tests were performed using about $10 \mathrm{~g}$ of samples in each reactor. All of the reservoirs and the reactors are scanned by connected pressure gauges (Sensys Co., pressures ranging to $10 \mathrm{MPa}, 0.1 \%$ of uncertainty) and recorded by simulating program. After injecting $\mathrm{CO}_{2}$ gas into the reactor, the pressure decreased as usual as sample's absorption proceeded. At equilibration, $\mathrm{CO}_{2}$ solubility is calculated by means of the Allpros program using coefficient factors from Ely et al. ${ }^{16 a}$ This method is similar to that of Kim et al. ${ }^{16 \mathrm{~b}}$ Each experiment was repeated 3 times to ensure reliability of data collected.

Theoretical calculation. The interactions between [ $\mathrm{C}_{2}$-mim] $\mathrm{OPh}$ and $\mathrm{CO}_{2}$ were theoretically investigated using a Gaussian 03 program. ${ }^{17}$ The geometry optimizations and thermodynamic corrections without including the bulk solvent effect were performed with hybrid Becke 3-Lee-Yang-Parr (B3LYP) exchangecorrelation functional with the $6-31+\mathrm{G}^{*}$ basis sets for $\mathrm{C}, \mathrm{H}, \mathrm{N}$, $\mathrm{B}$ and $\mathrm{O}$, and $6-31+\mathrm{G}^{\prime}$ basis sets for $\mathrm{F}$. In order to obtain the most stable geometries, all kinds of possible interaction patterns were optimized. No restrictions on symmetries were imposed on the initial structures. All stationary points were verified as minima by full calculation of the Hessian and a harmonic frequency analysis.

\section{Results and Discussion}

The $\mathrm{CO}_{2}$ solubility of $\left[\mathrm{C}_{4}-\mathrm{mim}\right] \mathrm{OPh}$ at various temperatures and pressures has been measured by VLE after the system has reached a steady equilibrium state, and the result has been depicted in Figure 2 in terms of $\mathrm{CO}_{2}$ mole fraction. [ $\mathrm{C}_{4}$-mim] OPh showed a typical physical absorption trend with a slight curvature at different temperatures and pressures. This curvature might have resulted from the slight chemical absorption cha-

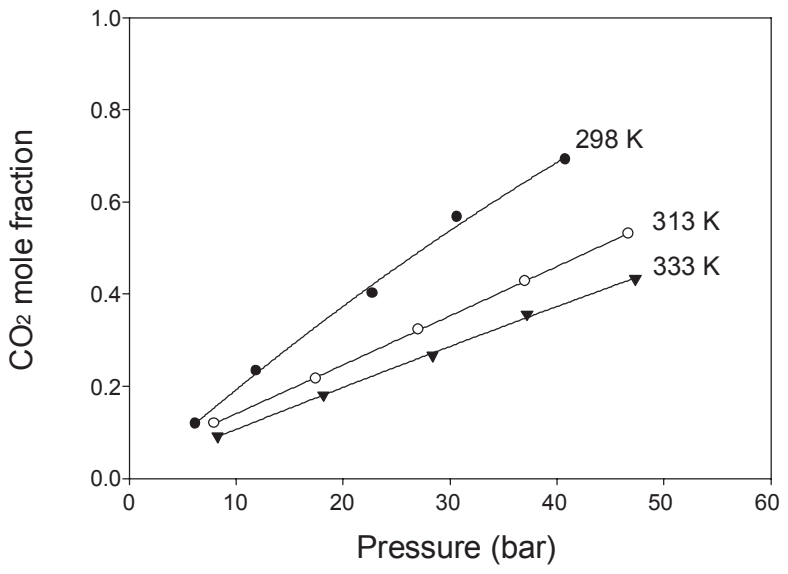

Figure 2. $\mathrm{CO}_{2}$ solubility of $\left[\mathrm{C}_{4}\right.$-mim $] \mathrm{OPh}$ at various temperatures and pressures. 


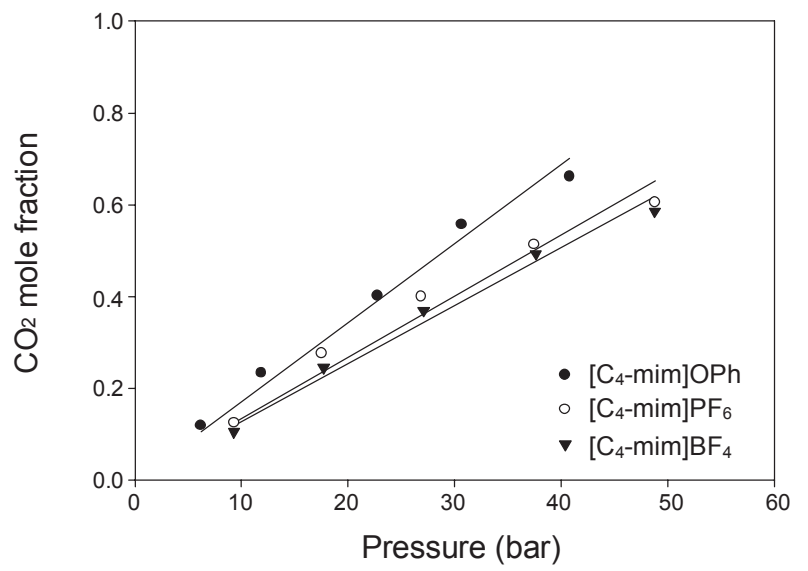

Figure 3. Comparison of $\mathrm{CO}_{2}$ solubility in $\left[\mathrm{C}_{4}-\mathrm{mim}\right] \mathrm{OPh}$ with $\left[\mathrm{C}_{4}-\mathrm{mim}\right]$ $\mathrm{PF}_{6}$ and $\left[\mathrm{C}_{4}-\mathrm{mim}\right] \mathrm{BF}_{4}$ at $298 \mathrm{~K}$.

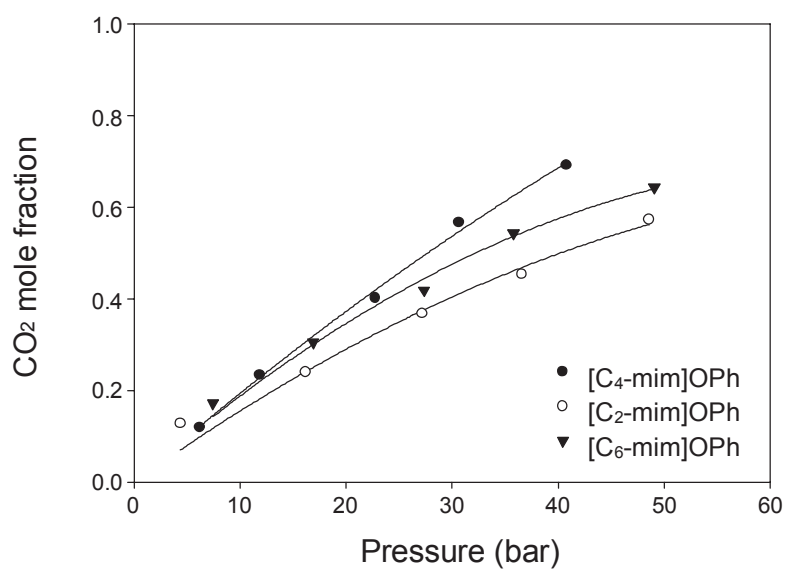

Figure 4. Comparison of $\mathrm{CO}_{2}$ solubility in $\left[\mathrm{C}_{4}-\mathrm{mim}\right] \mathrm{OPh}$ with $\left[\mathrm{C}_{2}-\mathrm{mim}\right]$ $\mathrm{OPh}$ and $\left[\mathrm{C}_{6}-\mathrm{mim}\right] \mathrm{OPh}$.

racter of the phenolate anion. $\mathrm{CO}_{2}$ solubiliy of $\left[\mathrm{C}_{4}-\mathrm{mim}\right] \mathrm{OPh}$ increased with decreasing temperature and increasing pressure. This trend seems to be common among most gases studied and among most chemical/physical sorbents used for the purpose. Also the $\mathrm{CO}_{2}$ mole fraction at $298 \mathrm{~K}$ becomes larger than 0.5 as we expected since this IL does not make a carbamate anion when interacting with $\mathrm{CO}_{2}$. However, the $\mathrm{CO}_{2}$ solubility at low pressures is not as high as we expected from the basicity of the phenolate anion.

Another test was performed with the change of anions of the ionic liquids. Figure 3 displays the comparison of $\mathrm{CO}_{2}$ solubility in $\left[\mathrm{C}_{4}-\mathrm{mim}\right] \mathrm{OPh}$ with $\left[\mathrm{C}_{4}-\mathrm{mim}\right] \mathrm{BF}_{4}$ and $\left[\mathrm{C}_{4}-\mathrm{mim}\right] \mathrm{PF}_{6}$. $\left[\mathrm{C}_{4}\right.$-mim $] \mathrm{BF}_{4}$ and $\left[\mathrm{C}_{4}-\mathrm{mim}\right] \mathrm{PF}_{6}$ are the mostly studied commercial ILs, and their $\mathrm{CO}_{2}$ solubilities are well-known in literatures. ${ }^{18}$ Present studies show that $\left[\mathrm{C}_{4}-\mathrm{mim}\right] \mathrm{OPh}$ has greater $\mathrm{CO}_{2}$ solubility than those of $\left[\mathrm{C}_{4}-\mathrm{mim}\right] \mathrm{BF}_{4}$ and $\left[\mathrm{C}_{4}-\mathrm{mim}\right] \mathrm{PF}_{6}$, and this suggests that using phenolate anion will be more attractive for the purpose of $\mathrm{CO}_{2}$ capture in future ILs. Kazarian et al. insisted that there are weak Lewis acid-base interactions between $\mathrm{CO}_{2}$ and ionic liquids, ${ }^{19}$ therefore ionic liquids with strongly basic anion are expected to have higher $\mathrm{CO}_{2}$ solubility. It also has been reported that anions of ILs are the most dominat- (a)

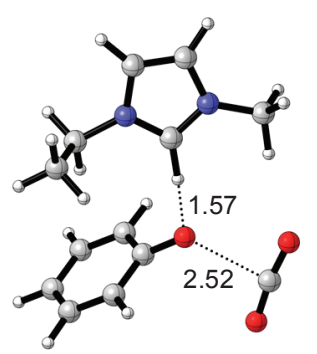

(b)

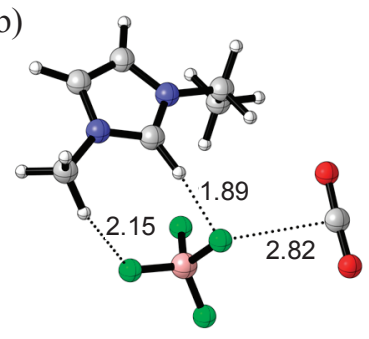

Figure 5. Optimized structures showing the interaction of $\left[\mathrm{C}_{2}-\mathrm{mim}\right] \mathrm{OPh}$ and $\left[\mathrm{C}_{2}\right.$-mim $] \mathrm{BF}_{4}$ with $\mathrm{CO}_{2}$ : (a) $\left[\mathrm{C}_{2}\right.$-mim $] \mathrm{OPh}$ with $\mathrm{CO}_{2}(\Delta \mathrm{H}=-3.6 \mathrm{kcal}$ $\left.\mathrm{mol}^{-1}\right)$, (b) $\left[\mathrm{C}_{2}-\mathrm{mim}\right] \mathrm{BF}_{4}$ with $\mathrm{CO}_{2}\left(\Delta \mathrm{H}=-1.9 \mathrm{kcal} \mathrm{mol}^{-1}\right)$.

ing factors that decide the nature of interaction with $\mathrm{CO}_{2} \cdot{ }^{20 \mathrm{a}, 20 \mathrm{~b}}$ Phenolate is an unusually strong basic anion and therefore expected to show high $\mathrm{CO}_{2}$ affinity.

Figure 4 displays the comparison of $\mathrm{CO}_{2}$ solubility in $\left[\mathrm{C}_{4}-\right.$ mim $] \mathrm{OPh}$ with $\left[\mathrm{C}_{2}-\mathrm{mim}\right] \mathrm{OPh}$ and $\left[\mathrm{C}_{6}-\mathrm{mim}\right] \mathrm{OPh}$. Among these three ILs, $\left[\mathrm{C}_{4}\right.$-mim] OPh showed the highest $\mathrm{CO}_{2}$ solubility. It is generally known that $\mathrm{CO}_{2}$ solubility of a physically absorbing ionic liquid increases as the alkyl chain of the cation gets longer due to the increase of "free volume" ${ }^{17}$ But in our case, [ $\mathrm{C}_{4}$-mim $] \mathrm{OPh}$ showed higher $\mathrm{CO}_{2}$ solubility than $\left[\mathrm{C}_{6}\right.$-mim $] \mathrm{OPh}$, and $\left[\mathrm{C}_{2}-\mathrm{mim}\right] \mathrm{OPh}$ showed the least affinity for $\mathrm{CO}_{2}$. The reason for this absorption order, which is different from typical physical absorption character, may be attributed to some chemical interaction between the phenolate anion and $\mathrm{CO}_{2}$ which gets hindered with longer alkyl chain. Further tests need to be performed before any conclusion can be made.

To explain the low solubility behavior of $\mathrm{CO}_{2}$ in $\left[\mathrm{C}_{\mathrm{n}}-\mathrm{mim}\right]$ $\mathrm{OPh}$, theoretical investigation was conducted at the B3LYP level of the theory $\left(6-31+\mathrm{G}^{*}\right.$ for $\mathrm{C}, \mathrm{H}, \mathrm{N}, \mathrm{B}$ and $\mathrm{O}$, and $6-31+\mathrm{G}^{\prime}$ for $\mathrm{F}$ ) using the Gaussian 03 program. $\left[\mathrm{C}_{2}\right.$-mim] $\mathrm{OPh}$ was used as a model compound for simplicity. The optimized structures showing the interactions of $\left[\mathrm{C}_{2}\right.$-mim] OPh with $\mathrm{CO}_{2}$ are depicted in Figure 5. As can be deduced from the experimental results, there exists a substantial interaction between the basic phenolate anion, $\mathrm{OPh}^{-}$and $\mathrm{C}_{2}-\mathrm{H}$ of the imidazolium ring. As can be seen from the optimized structure, $\mathrm{O}^{\cdot} \mathrm{C}_{2}-\mathrm{H}$ distance of $1.57 \AA$ is quite short compared with usual $\mathrm{O} \cdot{ }^{\cdot} \mathrm{C}_{2}-\mathrm{H}$ distance of $1.7 \sim 1.8 \AA$ in other ionic liquids. ${ }^{21}$ This strong hydrogen bonding interaction prevents phenolate anion from interacting with the acidic center of $\mathrm{CO}_{2}$. This might be the reason why we could not observe a strong chemical absorption behavior for the phenolate-based ionic liquid as expected from the basicity of the anion. Still the interaction enthalpy between the phenolate-based IL and $\mathrm{CO}_{2}$ is larger than that of physically absorbing IL such as $\left[\mathrm{C}_{2}-\mathrm{mim}\right] \mathrm{BF}_{4}$ as shown, which is in good agreement with the experimental absorption data.

Regeneration performance is one of the important factors to prove whether an absorbent is good to be used commercially. $\mathrm{CO}_{2}$ stripping condition from ILs is known to be much milder than that of conventional amine-based processes due to weak physical-bonding between $\mathrm{CO}_{2}$ and ILs. While most of the conventional chemical $\mathrm{CO}_{2}$ absorbents, such as amines, require high thermal energy, the energy requirement for regenerating the solvent and separating $\mathrm{CO}_{2}$ in case of ILs is much lower. 


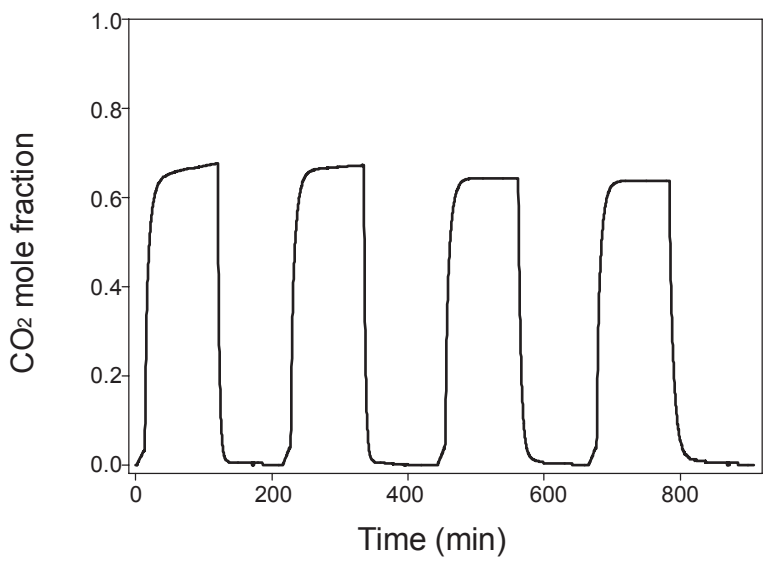

Figure 6. Regeneration performance of $\left[\mathrm{C}_{4}-\mathrm{mim}\right] \mathrm{OPh}$ at $298 \mathrm{~K}$.

Solvents exposed to degradation by high temperature regeneration condition become highly corrosive and environmentally hazardous. ${ }^{1}$ Ionic liquids, on the other hand, are known to be thermally stable and there is no need of intensive energy for their regeneration. Herein, regeneration test of [ $\left.\mathrm{C}_{4}-\mathrm{mim}\right] \mathrm{OPh}$ has been performed with simple stripping method and no heat up at all. After each $\mathrm{CO}_{2}$ absorption test, dissolved $\mathrm{CO}_{2}$ in ILs were stripped by pressure swing method using a vacuum pump connected to the reactors. After vacuuming the reactors for about $1 \mathrm{hr}$, the same absorption test was performed in a similar test condition with the formerly used ILs. Here, regeneration tests were performed four times continuously, and we could see the regeneration performance of $\left[\mathrm{C}_{4}-\mathrm{mim}\right] \mathrm{OPh}$ as seen in Figure 6. Test performed at $298 \mathrm{~K}$ and pressure up to $40 \mathrm{bar}$ show $\mathrm{CO}_{2}$ absorption capacity has rarely changed, and it proved that simple pressure swing method is enough for stripping $\mathrm{CO}_{2}$ from $\left[\mathrm{C}_{4}-\mathrm{mim}\right] \mathrm{OPh}$.

\section{Conclusion}

The solubility of $\mathrm{CO}_{2}$ in the ionic liquid $\left[\mathrm{C}_{\mathrm{n}}-\mathrm{mim}\right] \mathrm{OPh}(\mathrm{n}=$ $2,4,6$ ) has been measured by vapor-pressure equilibrium apparatus. The experimental results showed that $\left[\mathrm{C}_{4}-\mathrm{mim}\right] \mathrm{OPh}$ has much higher $\mathrm{CO}_{2}$ solubility than that of $\left[\mathrm{C}_{4}-\mathrm{mim}\right] \mathrm{BF}_{4}$ and $\left[\mathrm{C}_{4}-\right.$ $\operatorname{mim}] \mathrm{PF}_{6}$. The absorption capacity of the phenolate-based ionic liquid is lower than expected based on the basicity of the anion and this behavior is explained using theoretical method. Also simple pressure swing method is enough to regenerate IL.

Acknowledgments. We acknowledge financial support by a grant (CE3-101) from Carbon Dioxide Reduction \& Sequestration Research Center, one of the 21st Century Frontier R\&D Programs funded by the Ministry of Education, Science and Technology of Korean government.

\section{References}

1. Cho, M. H.; Lee, H. J.; Kim, H. G. Korean Chem. Eng. Res. 2010 , $48(1), 1$.

2. (a) Jung, S. K.; Kim, D. H.; Baek, I. H.; Lee, S. H. Korean Chem. Eng. Res. 2008, 46(3), 492. (b) Zhang, S.; Chen, Y.; Li, F.; Lu, X.; Dai, W.; Mori, R. Catal. Today 2006, 115, 61.

3. Wasserscheid, P.; Welton, T. Ionic Liquids in Synthesis; WileyVCH: Weinheim, 2003.

4. Lee, H. J.; Lee, J. S.; Ahn, B. S.; Kim, H. S. J. Ind. Eng. Chem. 2005, 16(5), 595.

5. Huang, J.; Rüther, T. Aust. J. Chem. 2009, 62, 298.

6. Xue, H.; Shreeve, J. M. Eur. J. Inorg. Chem. 2005, 2573.

7. Bate, E.; Mayton, R. D.; Ntai, I.; Davis, J. H. J. Am. Chem. Soc. 2002, 124, 926.

8. (a) Yu, G.; Zhang, S.; Yao, X.; Zhang, J.; Dong, K.; Dai, W.; Mori. R. Ind. Eng. Chem. Res. 2006, 45, 2875. (b) Huang, J.; Riisager, A.; Berg, R. W.; Fehrmann, R. J. Mol. Catal. A: Chem. 2008, 279, 170.

9. Palgunadi, J.; Im, J. K.; Kang, J. E.; Kim, H. S.; Cheong, M. Bull. Kor. Chem. Soc. 2010, 31(1), 146.

10. Keskin, S.; Kayrak-Taly, D.; Akman, U.; Hortaçsu, Ö. J. Supercrit. Fluid. 2007, 43, 150.

11. Palgunadi, J.; Kang, J. E.; Cheong, M.; Kim, H. G.; Lee, H. J.; Kim, H. S. Bull. Kor. Chem. Soc. 2009, 30(8), 1749.

12. (a) Davis, J. H. Chem. Lett. 2004, 33(9), 1072. (b) Bishnoi, S.; Rochelle, G. T. AIChE Journal 2002, 48(12), 2788.

13. Petermann, M.; Weissert, T.; Kareth, S.; Lösch, H. W.; Dreisbach, F. J. Supercrit. Fluid. 2008, 45, 156.

14. Welton, T. Chem. Rev. 1999, 99, 2071.

15. Cassol, C. C.; Ebeling, G.; Ferrera, B.; Dupont, J. Adv. Synth. Catal. 2006, 348, 243.

16. (a) Ely, J. F.; Magee, J. W.; Haynes, W. M. Thermophysical Properties for Special High $\mathrm{CO}_{2}$ Content Mixtures, Research Report110; Gas Processors Association: Tulsa, 1987. (b) Kim, Y. S.; Choi, W. Y.; Jang, J. H.; Yoo, K.-P.; Lee, C. S. Fluid Phase Equilibr. 2005, 228-229, 439.

17. Frisch, M. J.; Trucks, G. W.; Schlegel, H. B. et al. Gaussian 03, revision C.02, Gaussian, Inc., Pittsburgh, PA, 2004.

18. Muldoon, M. J.; Aki, S. N.; Anderson, J. L.; Dixon, J. K.; Brennecke, J. F. J. Phys. Chem. B 2007, 30, 9001

19. Kazarian, S. G.; Briscoe, B. J.; Welton, T. Chem. Commun. 2000, 2047.

20. (a) Aki, S. N. V. K.; Mellein, B. R.; Saurer, E. M.; Brennecke. J. F. J. Phys. Chem. B 2004, 108(52), 20355. (b) Cadena, C.; Anthony, J. K.; Shah, J. K.; Morrow, T. I.; Brennecke, J. F.; Maginn, E. J. J. Am. Chem. Soc. 2004, 126(16), 5300.

21. Lee, J. M.; Palgunadi, J.; Kim, J. H.; Jung, S.; Choi, Y.; Cheong, M.; Kim, H. S. Phys. Chem. Chem. Phys. 2010, 12, 1812. 